(2) Open Access Full Text Article

REVIEW

\title{
Development of oral agent in the treatment of multiple sclerosis: how the first available oral therapy, fingolimod will change therapeutic paradigm approach
}

\author{
This article was published in the following Dove Press journal: \\ Drug Design, Development and Therapy \\ 18 July 2012 \\ Number of times this article has been viewed
}

\section{Claudio Gasperini' \\ Serena Ruggieri ${ }^{2}$ \\ 'Department of Neurosciences, S Camillo Forlanini Hospital, \\ ${ }^{2}$ Department of Neurology and Psychiatry, University of Rome \\ "Sapienza," Rome, Italy}

Correspondence: C Gasperini Dipartimento Testa Collo, Azienda Ospedaliera S Camillo-Forlanini, Circonvallazione Gianicolense, 87,00152 Rome, Italy

Tel +390658704272

Email c.gasperini@libero.it

\begin{abstract}
Multiple sclerosis (MS) is a chronic inflammatory disorder of the central nervous system, traditionally considered to be an autoimmune, demyelinating disease. Based on this understanding, the initial therapeutic strategies were directed at immune modulation and inflammation control. At present, there are five licensed first-line disease-modifying drugs and two second-line treatments in MS. Currently available MS therapies have shown significant efficacy throughout many trials, but they produce different side-effect profiles in patients. Since they are well known and safe, they require regular and frequent parenteral administration and are associated with limited long-term treatment adherence. Thus, there is an important need for the development of new therapeutic strategies. Several oral compounds are in late-stage development for treating MS. Fingolimod (FTY720; Novartis, Basel, Switzerland) is an oral sphingosine-1-phosphase receptor modulator which has demonstrated superior efficacy compared with placebo and interferon $\beta$-1a in Phase III studies and has been approved in the treatment of MS. We summarily review the oral compounds in study, focusing on the recent development, approval and the clinical experience with FTY720.
\end{abstract}

Keywords: multiple sclerosis, oral compounds, fingolimod, fty 720 , sphingosine 1, phosphate, patient satisfaction

\section{Introduction}

Multiple sclerosis (MS) is a chronic, inflammatory, immune-mediated disease of the central nervous system (CNS). Disease onset usually occurs in young adults, and it is more common in females (3:1). The incidence of the disease varies worldwide, with a prevalence that ranges between 2 and 150 per 100,000 depending on the country or specific population, affecting up to 2.5 million people worldwide. ${ }^{1}$ Although the incidence varies, MS is the most nontraumatic common cause of neurological disability and impairment in young patients in Western Europe and North America. ${ }^{2}$

Most patients $(80 \%)$ present with a relapsing and remitting course (RRMS), which is characterized by recurring attacks of acute focal neurological deficits or exacerbations of existing deficits (relapses) followed gradually by partial or full recovery (remission). ${ }^{3}$ The multifocal nature of the disease manifests clinically as a range of sensorimotor, cerebellar, visual, sphincteric, brain stem, cognitive, and neuropsychiatric symptoms. After 10-20 years, approximately half of these patients convert to the secondary progressive (SPMS) phase of the disease, in which there is acceleration of disability accumulating irreversible neurologic deficits in the absence 
of clinical relapses. ${ }^{4}$ The remaining $20 \%$ with progressive clinical deterioration from the onset of the disease have primary progressive MS (PPMS).

Even though the immunopathogenesis of MS is complex and still unclear, it has been supposed that RRMS is characterized by strong inflammation activity and PPMS and SPMS are thought to be dominated by axonal degeneration in the absence of overt inflammation which is most likely a result of oxidative damage and/or increased susceptibility to injury caused by the process of myelin sheath loosening. ${ }^{5}$ Many different immune cells are involved in the pathogenesis of MS, including T cells, B cells, and macrophages. ${ }^{6}$ Given the prominence of inflammatory changes in acute MS lesions, therapy of the disease has focused particularly, for the past three decades, on anti-inflammatory strategies. Thus, seven compounds have once-daily licenses for treating MS and they especially target the inflammatory component of the disease. Thus all compounds licensed for treating MS have as principle target the inflammatory component of the disease.

Treatment of RRMS typically consists of direct symptom management, brief corticosteroid administration for acute exacerbations, and the regular use of disease-modifying drugs (DMDs). Currently approved immunomodulator treatments for RRMS include glatiramer acetate (GA) and recombinant interferons (IFN $\beta$ ) (IFN $\beta$-1a Avonex ${ }^{\circledR}$, IFN $\beta$-1a Rebif $^{\circledR}$, IFN $\beta$-1b Betaseron ${ }^{\circledR}$, Extavia $\left.{ }^{\circledR}\right)$ that represent the gold standard in modifying the course of MS. Natalizumab Mitoxantrone and fingolimod are also available for treatment of MS as second-line therapy in more severe disease. Since MS is a currently incurable, chronic disease, long-term DMD therapy requires commitment from patients to continue their treatment indefinitely. At present, all currently approved MS treatments are injected (subcutaneously or intramuscularly) or are given by intravenous infusion that can be associated with reduced convenience and compliance, and with injection- or infusion-related adverse effects (AEs). Nevertheless, in clinical practice, DMDs treatments are frequently associated with suboptimal response in terms of efficacy. The existing medications are only partially effective at preventing MS relapses and in particular, at slowing disability progression. Patients treated with interferons often experience several side effects and these DMDs for MS require long-term, regular injection or monthly parenteral infusions, which may be uncomfortable and inconvenient for the patient. ${ }^{7}$

Given the limitations of current interventions, management of MS could be significantly improved by new treatments that influence not only the immune system but also the pathologic changes in the CNS while also being amenable to oral administration, possibly avoiding the drawbacks of parenteral administration. Thus there is an important need for new therapeutic strategies, not only those that may offer greater patient satisfaction such as oral medications and monoclonal antibodies, but also agents intended to promote neuroprotection and neurorepair. Fingolimod (FTY720) could be one such potential treatment, combining these both aspects. The objective of the present paper is to review compounds that have successfully completed Phase III clinical trials and to focus on FTY720, which has recently been approved.

\section{Oral MS therapies in development}

A number of potential therapies for MS are now in late-stage development. New and novel therapeutic agents are being trialed in MS centers worldwide. These include not only oral agents for relapsing and progressive forms of the disease, but also monoclonal antibodies. To improve adherence to DMD and especially to improve the therapeutic compliance and quality of life of patients, the development of oral agents would be welcome if they are at least as effective as the currently available injectable therapies. Several oral therapies are currently under evaluation in clinical trials. The most promising agents are listed in Table 1.

Within these compounds, two agents have already been submitted for regulatory approval (fingolimod, cladribine), with different outcomes. Regulatory applications for fingolimod were submitted in December 2009 and the drug received approval from the FDA on September 21, 2010. ${ }^{8}$ On January 20, 2011, the Committee for Medicinal Products for Human Use (CHMP) adopted a positive opinion, recommending that a marketing authorization for fingolimod be granted, intended for the treatment of adult patients with RRMS with high disease activity. At present, fingolimod is available in Russia and the US.

Applications for cladribine as an oral therapy for MS were submitted to the European Medicines Agency and the US FDA in 2009. However, in December 2009, the FDA issued a "refuse to file" letter to the manufacturers of cladribine (Merck KGaA) indicating that additional information was required before a further application could be submitted. In July 2010, the FDA accepted the resubmitted cladribine application and granted the drug priority review status. In the same month, the Russian Federal Service on Surveillance in Healthcare and Social Development approved cladribine for use in RRMS with a similar approval being granted by the Australian Therapeutic Goods Administration in September 2010. ${ }^{9}$ Yet cladribine received a negative European recommendation by the CHMP on September 23, 
Table I Summary of oral therapies in late stage development (Phase III) for the treatment of multiple sclerosis

\begin{tabular}{|c|c|c|c|}
\hline Compound & Dose regimen & Molecule and mechanism & Potential adverse effects \\
\hline Cladribine & $\begin{array}{l}\text { Once daily for } \\
2-4 \text { weeks per year }\end{array}$ & $\begin{array}{l}\text { Adenosine deaminase-resistant purine nucleoside analog; } \\
\text { preferentially reduces lymphocyte subpopulations; produces } \\
\text { sustained reduction of lymphocyte } T \text { and B subtypes }\end{array}$ & $\begin{array}{l}\text { Myelosuppression and } \\
\text { infection }\end{array}$ \\
\hline BG-12 & $\begin{array}{l}\text { Three times a day, } \\
\text { every day }\end{array}$ & $\begin{array}{l}\text { Unsaturated dicarboxylic acid, isomeric to maleic acid; } \\
\text { appears to induce depletion of peripheral blood leukocytes } \\
\text { owing mainly to a reduction of T cells; neuroprotective effects }\end{array}$ & Hepatotoxicity \\
\hline Teriflunomide & Once daily, every day & $\begin{array}{l}\text { Active metabolite of leflunomide; blocks de novo pyrimidine } \\
\text { synthesis by inhibiting dihydroorotate dehydrogenase in } \\
T \text { cell and other rapidly dividing cell populations, leading } \\
\text { to a decrease in DNA synthesis }\end{array}$ & $\begin{array}{l}\text { Pancytopenia, } \\
\text { hepatotoxicity }\end{array}$ \\
\hline $\begin{array}{l}\text { Laquinimod } \\
\text { (ABR-2I5062) }\end{array}$ & Once daily, every day & $\begin{array}{l}\text { Modulates the balance of the T-helper (Th) cells I and 2; } \\
\text { induction of transforming growth factor } \beta \text {; inhibits infiltration } \\
\text { of Cd4+ T cells and macrophages into CNS }\end{array}$ & $\begin{array}{l}\text { Hepatotoxicity, } \\
\text { proinflammation }\end{array}$ \\
\hline $\begin{array}{l}\text { Fingolimod } \\
\text { (FTY720) }\end{array}$ & Once daily, every day & $\begin{array}{l}\text { Structural analog of sphingosine I-phosphate receptor } \\
\text { agonist myriocin; interferes with cell traffic between } \\
\text { organs and blood, preventing migration to target sites }\end{array}$ & $\begin{array}{l}\text { Lymphopenia, infection, } \\
\text { bradycardia, increased airway } \\
\text { resistance, macular edema, } \\
\text { hepatotoxicity }\end{array}$ \\
\hline
\end{tabular}

2010. Following this feedback from regulatory authorities, it has become challenging for the company to continue pursuing the global approval process of cladribine tablets.

\section{Cladribine}

Cladribine, a synthetic deoxyadenosine analog, is an oral immunomodulatory agent that produces targeted, sustained reduction of $\mathrm{T}$ and $\mathrm{B}$ lymphocytes. Cladribine is already approved for the treatment of leukemias and lymphomas.

Short-course therapy with cladribine tablets was investigated for RRMS in the CLARITY study (CLAdRIbine Tablets treating multiple sclerosis orallY). CLARITY was a Phase III, randomized, double-blind, placebo-controlled, multicenter, 96-week study with three parallel groups to assess the efficacy of cladribine tablets in patients with RRMS according to the diagnostic McDonald criteria. The cladribine tablets dosing regimen consisted of two or four short courses per year (cumulative dose of 3.5 and $5.35 \mathrm{mg}$ / $\mathrm{kg}$ over the 96-week study, respectively). Treatment with 3.5 and $5.25 \mathrm{mg} / \mathrm{kg}$ cladribine tablets significantly reduced the annualized relapse rate (relative reduction: $57.6 \%$ and $54.5 \%$ vs placebo, respectively, both $P<0.001)$ and resulted in significantly more relapse-free patients $(79.7 \%$ and $78.9 \%$ vs $60.9 \%$, respectively; odds ratio [OR]: 2.53 and 2.43 , both $P<0.001) .{ }^{10}$ Three outcomes of activity were detected on magnetic resonance imaging (MRI): $\mathrm{T} 1$ gadolinium-enhancing lesions, active T2 lesions, and combined unique lesions (all $P<0.001$ vs placebo). Lymphopenia occurred more frequently in patients treated with cladribine tablets at both dosages than with placebo. ${ }^{11}$ Despite the lymphopenia, the overall incidence of infections was similar across treatment groups. There were no cases of herpes zoster in the placebo group compared with eight and 12 cases of herpes zoster in the $3.5 \mathrm{mg} / \mathrm{kg}$ and $5.35 \mathrm{mg} / \mathrm{kg}$ groups, respectively. However, all cases were dermatomal and self-limiting. Neoplasms occurred in ten cases, all of them in cladribine-treated patients at both doses, compared with no patients in the placebo group. One patient treated with cladribine tablets had reactivation of latent tuberculosis and died. The use of cladribine may have contributed to this reactivation, and tuberculosis screening measures were immediately introduced subsequently.

\section{Fumaric acid}

Fumaric acid (FA), BG12, is an unsaturated dicarboxylic acid, isomeric to maleic acid, which acts as an intermediate in the Krebs cycle. Its exact mechanism of action is still unclear, but it appears to induce depletion of peripheral blood leukocytes owing mainly to a reduction in number of $\mathrm{T}$ cells.

In vitro studies indicate that fumaric acid esters (FAEs) induce a shift from $\mathrm{T}$ helper (Th) 1 to Th2 cytokines as part of their treatment effect. ${ }^{12}$ In an open-label, prospective study involving ten patients with RRMS, FA produced significant reductions from baseline in the number $(P<0.05)$ and volume $(P<0.01)$ of $\mathrm{Gd}$-enhancing lesions after 18 weeks of treatment with a target dose of $720 \mathrm{mg} /$ day; this effect persisted throughout the second 48-week treatment phase at half the target dose, following a 4-week washout period. ${ }^{13}$

In a 24-week, double-blind, randomized, placebocontrolled Phase IIb study in RRMS patients ( $\mathrm{n}=257)$, MRI analysis revealed a significant and dose-dependent reduction of brain lesion activity, particularly after treatment with the 720-mg dosage. In comparison to placebo, this group 
demonstrated $\sim 70 \%$ reduction in Gd-enhancing lesions and a $50 \%$ reduction in new or enlarging $\mathrm{T} 2$ lesions and new T1 hypointense lesions. ${ }^{14}$ The most commonly observed AEs were flushing, nasopharyngitis, headache, nausea, diarrhea, fatigue, pruritus, upper abdominal pain, and hot flush, with evidence of a dose-related influence on the frequency of most of these AEs.

A multicenter, 2-year randomized, double-blind, placebocontrolled, dose-comparison, Phase III study was started in Europe and in North America to determine the long-term safety and efficacy of BG-12. This included the DEFINE (Efficacy and Safety of Oral BG00012 in RelapsingRemitting Multiple Sclerosis) and the CONFIRM (Efficacy and Safety Study of Oral BG00012 With Active Reference in Relapsing-Remitting Multiple Sclerosis) trials, which also contained a GA group to compare BG-12 with an established therapy. The DEFINE study has been completed and results will soon be reported.

\section{Teriflunomide}

Teriflunomide is the active metabolite of leflunomide. Leflunomide blocks de novo pyrimidine synthesis by inhibiting dihydroorotate dehydrogenase in $\mathrm{T}$ cell and other rapidly dividing cell populations, leading to a decrease in DNA synthesis. ${ }^{15}$ Leflunomide is licensed for the treatment of rheumatoid arthritis and is also effective in experimental autoimmune neuritis and rat experimental autoimmune encephalomyelitis (EAE). ${ }^{16,17}$

A 36-week, randomized, double-blind, placebo-controlled, parallel-group trial assessed the safety and efficacy of this new drug on MS patients. One hundred and seventy-nine patients (157 with RRMS, 29 with SPMS) were treated with the following: placebo $(\mathrm{n}=61)$, teriflunomide $7 \mathrm{mg}$ /day ( $\mathrm{n}=61)$, teriflunomide $14 \mathrm{mg} /$ day $(\mathrm{n}=57)$ for 36 weeks. Treatment with teriflunomide 7 or $14 \mathrm{mg}$ /day resulted in significant suppression of $>61 \%$ of MRI activity relative to placebo ( $P<0.03$ at $7 \mathrm{mg} /$ day and $P<0.001$ at $14 \mathrm{mg} /$ day $)$. The annualized relapse rate between placebo and teriflunomide $14 \mathrm{mg}$ /day was similar to that reported for IFN- $\beta$ and GA $(32 \%)$. The higher dose of teriflunomide (14 mg/day) appears to be more effective than the $7 \mathrm{mg} /$ day dose, in terms of relapse rate, although no dose effect was observed on primary endpoints such as Gd-enhancing lesions and new/enlarging T2 lesions. ${ }^{18}$ A large randomized, doubleblind, placebo-controlled Phase III parallel group study has recently been completed (TEMSO). Patients with RRMS or PRMS $(n=1088)$ were randomized $(1: 1: 1)$ to receive placebo, teriflunomide $7 \mathrm{mg} /$ day or $14 \mathrm{mg}$ /day for 108 weeks.
The annualized relapse rates were $0.539,0.370$, and 0.369 in the placebo, $7 \mathrm{mg}$, and $14 \mathrm{mg}$ groups, respectively. Thus, the relative risk reductions in the $7 \mathrm{mg}$ and $14 \mathrm{mg}$ groups versus placebo were $31.2 \%(P=0.0002)$ and $31.5 \%(P=0.0005)$, respectively. Sustained disease progression was reached in $27.3 \%$ of the placebo patients, in $21.7 \%$ of the $7 \mathrm{mg}$ patients, and in $20.2 \%$ of the $14 \mathrm{mg}$ patients. The relative risk for sustained progression was significantly reduced by $29.8 \%$ versus placebo only in the 14 -mg group $(P=0.0279) .{ }^{19}$ AEs reported more frequently in the treatment groups than in the placebo group were: neutropenia, nasopharyngitis, alopecia, nausea, increase in alanine aminotransferase, paresthesia, back and limb pain, diarrhea, and arthralgia.

Trials investigating teriflunomide in clinically isolated syndrome are underway as combination studies of teriflunomide with IFN- $\beta$ or GA. This combination study seems to be really meaningful, as it explores the possibility of using teriflunomide as add-on therapy.

\section{Laquinimod}

Laquinimod is a novel synthetic compound with oral bioavailability, that is in development as an oral formulation for the treatment of MS. Laquinimod was effective in a rat model of EAE, in which its efficacy was ascribed to modulation of the balance of Th1 and Th2 cells inducting the transforming growth factor $\beta .^{20}$ However, the exact mechanism of action in MS patients is still unclear. The efficacy of laquinimod was studied in two Phase II studies. The first Phase II trial showed inconclusive results on the effect of the $0.3 \mathrm{mg}$ dose and led to further exploration of the therapeutic dose in an additional Phase IIb study. The second study was a Phase IIb, multinational, randomized, double-blind, parallel-group, placebo-controlled 36-week study, evaluating the efficacy, tolerability, and safety of two daily oral doses ( 0.3 and $0.6 \mathrm{mg}$ ) of laquinimod (as compared to placebo) in subjects with RRMS. Three hundred and six patients were randomized, 98 subjects to laquinimod $0.3 \mathrm{mg}, 106$ to laquinimod $0.6 \mathrm{mg}$, and 102 to placebo. The statistical analysis on the intention-to-treat (ITT) population for the primary endpoint demonstrated a statistically significant treatment effect of laquinimod $0.6 \mathrm{mg}$ compared to placebo $(P=0.0048)$, with a reduction of $40 \%$ in the cumulative number of Gd-enhancing lesions at weeks 24, 28, 32, and 36. A nonsignificant treatment effect of $8 \%$ was observed with laquinimod $0.3 \mathrm{mg}$ $(P=0.6740)$. A statistically significant reduction of treatment effect of laquinimod 0.6 compared to placebo was demonstrated for other MRI-related endpoints, defined in the protocol as secondary endpoints. ${ }^{21}$ Given these results, 
the sponsor has moved forward with Phase III clinical trials of laquinimod at the $0.6 \mathrm{mg} /$ day dose.

Based on a thorough review of all laquinimod clinical data available to date, the primary safety concerns include potential hepatotoxicity and a possible pro-inflammatory effect. Four serious AEs (SAEs) were reported: pleuritis, BuddChiari syndrome, pituitary adenoma with hemorrhage, and a possible diagnosis of Crohn's disease. Pharyngolaryngeal pain, dyspepsia, and ankle edema were also observed. Laboratory abnormalities seen in Phase II laquinimod studies include elevated white blood count, elevated fibrinogen levels, and a trend towards decreased hemoglobin, elevated liver enzymes, and increased amylase. The first of the two Phase III studies of laquinimod is called ALLEGRO, a multinational, multicenter, randomized, double-blind, placebo-controlled study evaluating the safety and efficacy of laquinimod $0.6 \mathrm{mg} /$ day in RRMS.

Analysis of the primary endpoint in the completers and evaluable cohorts showed a reduction in annualized relapse rate $(\mathrm{ARR})$ of $23 \%(P<0.0024)$. Statistically significant differences have been detected in terms of sustained progressions and brain atrophy, with a $32.8 \%$ reduction of brain loss in the treatment group $(P<0.0001)^{22}$. The second Phase III study (BRAVO), is a multinational, multicenter, randomized, parallel-group study in RRMS to assess the efficacy, safety, and tolerability of laquinimod $0.6 \mathrm{mg} /$ day compared with placebo in a double-blind design and with IFN-b-1a (Avonex) in a rater-blinded design. The present study showed sustained 3-month confirmed progression of disability, a $33.5 \%$ reduction for laquinimod versus placebo $(P=0.04)$, and a $28.7 \%$ reduction $(P=0.09)$ with IFN versus placebo. An additional adhoc analysis to examine how robust this finding was, showed a similar effect on 6-month confirmed progression of disability, with a $40.6 \%$ reduction with laquinimod $(P$ $=0.04)$ versus placebo and a $28.3 \%$ reduction with IFN versus placebo $(P=0.14)$. There was a $22 \%$ reduction with laquinimod versus placebo $(P=0.062)$ in $\mathrm{Gd}+\mathrm{T} 1$ lesions of Gd enhancing lesions and a $19 \%$ reduction in new T2 lesions $(P=0.037)$. As would be expected based on prior experience, the IFN had an even larger effect on these parameters, with a $60 \%$ reduction in $\mathrm{Gd}+$ lesions and a $52 \%$ reduction in $\mathrm{T} 2$ lesions. ${ }^{23}$

All the Phase III trials regarding the drugs described above have been recently completed and are waiting for regulatory approval. In the next section, we focus on fingolimod which has been recently approved both in the US and Europe and could change the therapeutic treatment of MS.

\section{Introduction to the compound}

Fingolimod (FTY720) is an oral drug with a novel mechanism of action and unique immunological and neurobiological properties. Fingolimod is a structural analog of sphingosine that does not impair $\mathrm{T}$ and $\mathrm{B}$ cell activation, proliferation, and effective function, but interferes with cell traffic between lymphoid organs and blood. ${ }^{24}$ Moreover fingolimod is a lipophilic compound that can cross the blood-brain barrier, and research suggests that its neuroprotective properties might be a reflection of its ability to directly interact with specific receptors on neurons and glia. ${ }^{25}$ Following preclinical studies in animal models of organ transplantation, fingolimod was first evaluated for the prevention of allograft rejection in renal transplant patients, but Phase III trials failed to show benefit over standard treatments. ${ }^{26}$ The encouraging results obtained from animal models of experimental autoimmune encephalomyelitis (EAE) provided the rationale for clinical evaluation in humans, and one Phase II proof-of-concept study confirmed the favorable effect of fingolimod oral therapy on standardized measures of disease activity in patients with RRMS.

\section{Chemistry and pharmacodynamics}

Fingolimod (2-amino-2-[2-(4-octylphenyl)ethyl]-1,3propanediol) is an immunosuppressive natural product derived from myriocin, a metabolite isolated from the fungus Isaria sinclairii, used as a drug in Oriental medicine. ${ }^{27}$ This compound is a sphingosine-1-phosphate $(\mathrm{S} 1 \mathrm{P})$ receptor modulator. $\mathrm{S} 1 \mathrm{P}$ is produced by the phosphorylation of sphingosine by ubiquitously expressed sphingosine kinases, a breakdown product of the cell membrane constituent sphingomyelin. It is present at concentrations of 100 to $1000 \mathrm{nmol} / \mathrm{L}$ in blood and, as with most small lipids, is preferentially bound to albumin and other plasma proteins. ${ }^{28} \mathrm{~S} 1 \mathrm{P}$ could act both as second messenger and as an extracellular ligand for a family of plasma membrane G protein-coupled receptors (GPCR). ${ }^{29}$ There are five known $\mathrm{S} 1 \mathrm{P}$ receptor subtypes, $\mathrm{S}_{1} \mathrm{P}_{1-5}$, and these are expressed on a wide range of cell types, including lymphocytes and neural cells (Table 2). Each S1P receptor subtype is associate with at least one subclass of $\mathrm{G}$ protein, which activate different intracellular signaling pathways. ${ }^{30}$ The receptors $\mathrm{S}_{1} \mathrm{P}_{1-3}$ are widely expressed by a variety of tissues, whereas $\mathrm{S}_{4} \mathrm{P}_{4}$ is exclusively found on lymphoid and hematopoietic tissues and $\mathrm{S}_{1} \mathrm{P}_{5}$ is mainly expressed in the CNS. ${ }^{31}$ The ubiquitous expression of S1P receptors and their coupling to different $\mathrm{G}$ proteins explains the varied biological effects of the S1P/S1P-receptor system. ${ }^{32}$ In particular, S1P1 expressed on lymphocytes regulates the normal departure of 
Table 2 Distribution and functions of SIP receptors ${ }^{26}$

\begin{tabular}{|c|c|c|c|}
\hline Receptors & Cellular distribution & Fingolimod binding & Key functions \\
\hline SIP $_{1}$ (EDGI) & $\begin{array}{l}\text { - Lymphocytes, mast cells, eosinophils; } \\
\text { - Neurons, astrocytes oligodendrocytes microglia; } \\
\text { - Atrial myocytes, endothelium smooth muscle cells, } \\
\text { Schwann cells }\end{array}$ & Yes & $\begin{array}{l}\text { - Lymphocyte egress from secondary } \\
\text { lymphoid organs } \\
\text { - Neural cell migration/function } \\
\text { - Embryonic development of } \\
\text { cardiovascular and nervous systems } \\
\text { - Blood vessel formation } \\
\text { - Endothelial barrier function }\end{array}$ \\
\hline $\mathrm{SIP}_{2}$ (EDG5) & $\begin{array}{l}\text { - Neurons, microglia, astrocytes } \\
\text { - Smooth muscle cells, Schwann cells }\end{array}$ & No & $\begin{array}{l}\text { - Vascular tone } \\
\text { - Endothelial barrier function } \\
\text { - Inner ear maintenance affecting hearing } \\
\text { and balance } \\
\text { - Nerve conduction }\end{array}$ \\
\hline $\mathrm{SIP}_{3}(\mathrm{EDG} 3)$ & $\begin{array}{l}\text { - Neurons, astrocytes microglia } \\
\text { - Atrial myocytes, endothelium, smooth muscle cells } \\
\text { - Lung } \\
\text { - Kidney } \\
\text { - Intestine } \\
\text { - Cartilage } \\
\text { - Schwann cells }\end{array}$ & Yes & $\begin{array}{l}\text { - Endothelial barrier function } \\
\text { - Neural cell migration/function }\end{array}$ \\
\hline $\mathrm{SIP}_{4}$ (EDG6) & $\begin{array}{l}\text { - Leukocytes } \\
\text { - Schwann cells }\end{array}$ & Yes & Unknown \\
\hline $\mathrm{SIP}_{5}$ (EDG8) & $\begin{array}{l}\text { - Oligodendrocytes, microglia } \\
\text { - Astrocytes }\end{array}$ & Yes & $\begin{array}{l}\text { - Oligodendrocyte function } \\
\text { - Natural killer cell migration }\end{array}$ \\
\hline
\end{tabular}

Abbreviations: EDG, endothelial differentiation sphingolipid G-protein-coupled receptor; NK, natural killer; SIP, sphingosine-I-phospate.

lymphocytes from lymphoid tissues, ${ }^{33}$ whereas S1P receptors expressed in the CNS have been shown to modulate several functions, such as neurogenesis, neural function, and migration. ${ }^{31}$ This may explain the possible clinical AEs that agents targeting the S1P receptor system, including fingolimod, can potentially induce. As a structural analog of natural sphingosine, fingolimod after ingestion can undergo rapid phosphorylation in vivo, especially in the liver, by sphingosine kinase-2 to produce the phosphorylated form of the compounds. The latest can bind four of the five receptor subtypes with high affinity: $\mathrm{S}_{1} \mathrm{P}_{1}, \mathrm{~S}_{1} \mathrm{P}_{3}, \mathrm{~S}_{1} \mathrm{P}_{4}$, and $\mathrm{S}_{1} \mathrm{P}_{5}{ }^{34}$ After the interaction with the agonist, the S1P1 receptor is internalized and can no longer bind to its natural circulating ligand, S1P, inducing a long-lasting internalization, ubiquitination, and intracellular degradation of the receptors, rendering the cells unresponsive to endogenous $\mathrm{S}^{\mathrm{P}}{ }^{35}$ The effects of fingolimod reflect the ubiquitous expression of S1P receptors and is shown on different levels, primarily the immune system and CNS. Following administration, blood concentration increases slowly to reach peak values at 8-36 hours post-dosing. The elimination half-life of fingolimod averages 8.8 days, so a once-daily dosing is permitted. Clearance of fingolimod depends mainly on hepatic oxidative metabolism and none of the identified metabolites possess immunomodulatory activity. ${ }^{35}$ The main pharmacodynamic effect of fingolimod consistently observed in human studies has been temporary reversible lymphopenia. ${ }^{36,37}$

\section{Clinical efficacy}

On the basis of the demonstrated potency of fingolimod in human organ transplantation, ${ }^{37}$ preclinical studies in various EAE models were designed. ${ }^{38}$ These studies demonstrated the capability of fingolimod in preventing and treating EAE. Delivery of fingolimod from the day of immunization or at a presymptomatic disease stage prevents the development of neurological signs in both monophasic and relapsing forms of EAE. ${ }^{38,39}$ Fingolimod is currently being assessed in one of the largest Phase III MS study programs ever undertaken, having shown promise in a Phase II, 6-month placebo-controlled study in patients with relapsing MS in which oral fingolimod, when compared with placebo, significantly reduced ARR and inflammatory activity according to MRI scans (Table 3).

\section{Phase II studies}

The first study evaluating the activity of fingolimod in patients with RRMS was a randomized, double-blind, placebo-controlled, 6-month study. ${ }^{40}$ The study was designed to explore safety and tolerability, and the treatment effect on MRI lesion parameters but not clinical outcomes. In the core study, patients were randomly assigned, in a 1:1:1 
Table 3 Summary of fingolimod trials

\begin{tabular}{|c|c|c|c|c|c|}
\hline$\overline{\text { Study }}$ & Study design & Treatment in study & Primary endpoints & Eligibility criteria & Main results \\
\hline Kappos et al ${ }^{40}$ & $\begin{array}{l}\text { Phase II, 6-month, } \\
\text { double-blind, } \\
\text { parallel-group, } \\
\text { placebo-controlled, } \\
\text { multicenter }\end{array}$ & $\begin{array}{l}\text { Fingolimod } 5 \mathrm{mg} \mathrm{po,} \mathrm{qd} \\
\text { Fingolimod } \\
\mathrm{I} .25 \mathrm{mg} \text { po, qd } \\
\text { Placebo }\end{array}$ & $\begin{array}{l}\text { Total no of Gd+ } \\
\text { lesions on TIW } \\
\text { MRI at month } 6\end{array}$ & $\begin{array}{l}\text { RRMS, SPMS } \\
\text { I8-60 years } \\
\text { EDSS 0-6, no } \\
\text { evidence of relapse } \\
\text { in the last } 30 \text { days }\end{array}$ & $\begin{array}{l}\text { Patients free from } \\
\text { Gd+ lesions: } 82 \% *\end{array}$ \\
\hline $\begin{array}{l}\text { Cohen et al, } \\
\text { (TRANSFORMS) }^{43}\end{array}$ & $\begin{array}{l}\text { Phase III, I2-month, } \\
\text { double-blind, } \\
\text { double-dummy, } \\
\text { parallel-group, } \\
\text { active-controlled, } \\
\text { multicenter }\end{array}$ & $\begin{array}{l}\text { Fingolimod } \\
\text { I. } 25 \mathrm{mg} \text { po, qd } \\
\text { Fingolimod } \\
0.5 \mathrm{mg} \text { po, qd } \\
\text { IFNBeta- Ia } 30 \mu \mathrm{g} \\
\text { im, qw }\end{array}$ & $\begin{array}{l}\text { ARR over } \\
\text { I } 2 \text { months }\end{array}$ & $\begin{array}{l}\text { RRMS } \\
\text { I } 8-55 \text { years } \\
\text { EDSS } 0-5.5 \text {, recent } \\
\text { history of relapse }\end{array}$ & $\begin{array}{l}\text { ARR: } 0.20^{*} ; 0.16^{*} \\
\text { Patients free from } \\
\text { relapses: } 79.8 \% * ; 82.6^{*}\end{array}$ \\
\hline $\begin{array}{l}\text { Kappos et al, } \\
\text { (FREEDOMS) }^{44}\end{array}$ & $\begin{array}{l}\text { Phase III, 24-month, } \\
\text { double-blind, } \\
\text { parallel-group, } \\
\text { placebo-controlled, } \\
\text { multicenter }\end{array}$ & $\begin{array}{l}\text { Fingolimod } \\
1.25 \mathrm{mg} \text { po, qd } \\
\text { Fingolimod } \\
0.5 \mathrm{mg} \text { po, qd } \\
\text { Placebo }\end{array}$ & $\begin{array}{l}\text { ARR over } \\
24 \text { months }\end{array}$ & $\begin{array}{l}\text { RRMS } \\
\text { I8-55 years } \\
\text { EDSS } 0-5.5 \text {, recent } \\
\text { history of clinical } \\
\text { relapse }\end{array}$ & $\begin{array}{l}\text { ARR: } 0.16^{*} ; 0.18^{*} \\
\text { Patients free from } \\
\text { relapses: } 74.7 \pm 2.2 \%^{*} \\
70.4 \pm 2.3^{*}\end{array}$ \\
\hline
\end{tabular}

Note: $* P<0.001$.

Abbreviations: ARR, annualized relapse rate for confirmed relapses; EDSS, Expanded Disability Status Scale; Gd+, Gadolinium-enhanced; IFNBeta-Ia, interferon-b-Ia; im, intramuscular; MRI, magnetic resonance imaging; po, orally; qd, every day; qw, once a week; RRMS, relapsing-remitting multiple sclerosis; SPMS, secondary progressive multiple sclerosis; TIW, TI-weighted.

ratio, to $1.25 \mathrm{mg}$ of fingolimod, $5.0 \mathrm{mg}$ of fingolimod, or a matching placebo once daily given as oral capsules. The intention-to-treat (ITT) population comprised 277 patients of which 255 (92\%) completed the study. The primary endpoint of the study was the total number of Gd-enhanced lesions per patient recorded on T1-weighted MRI at monthly intervals for 6 months. Secondary MRI variables included the total volume of Gd-enhanced lesions per patient, the proportion of patients with Gd-enhanced lesions, the total number of new lesions per patient on T2-weighted images, changes in lesion volume on T2-weighted images, and brain volume from baseline to month 6 . Clinical endpoints included the number of patients remaining free of relapse, the ARR, and the time to the first relapse.

The total cumulative numbers of lesions per patient on post-baseline, monthly Gd-enhanced, T1-weighted MRI scans were lower in both fingolimod groups than in the placebo group $(P<0.001$ for the $1.25-\mathrm{mg}$ dose and $P=0.006$ for the 5.0-mg dose). At month 6 , the proportion of patients who were free of Gd-enhanced lesions was greater in both fingolimod groups than in the placebo group $(P<0.001$ for both comparisons). Regarding the clinical endpoint, significant improvements over placebo were observed in the fingolimod groups, including a relative reduction in the ARR (by $53 \%$ in the $5.0-\mathrm{mg}$ group and by $55 \%$ in the 1.25-mg group).

After the core study completion, patients could enter a dose open-label, uncontrolled, active-drug study extension. Placebo recipients were re-randomized to one of the FTY720 doses; those already receiving FTY720 continued at the same dose. ${ }^{41,42}$ During the study visits over months $15-24$, patients receiving FTY720 5.0 mg were switched to $1.25 \mathrm{mg}$ because a benefit-risk assessment indicated that the higher dose offered no efficacy advantage and possibly a less favorable safety profile.

Of the 250 patients who entered the extension, 189 (75.6\%) completed to month 24 and 173 (69\%) to month 36. In the group of patients who switched from the placebo group to the fingolimod group, the number of Gd-enhanced lesions decreased markedly following initiation of fingolimod treatment to 0.4 at month 12 and remained low $(0.1)$ at month 36. The relapse rate decreased to a level comparable with that of patients treated with fingolimod in the core study. The proportion of patients free from Gd-enhanced lesions in the placebo/fingolimod group was $50 \%$ at baseline, $47 \%$ at month 6 , and $89 \%$ at month 36 . The proportions of patients free from Gd-enhanced lesions in the fingolimod $1.25 \mathrm{mg}$ and $5.0 / 1.25 \mathrm{mg}$ groups at baseline were $52 \%$ and $48 \%$, respectively; at month 36 , the corresponding proportions were $88 \%$ and $89 \%$, respectively. In the continuous fingolimod groups, the mean number of Gd-enhanced lesions was 3.2 at baseline, 1.4 at month 6 , and 0.2 at month 36 in the $1.25 \mathrm{mg}$ group, and 2.6 at baseline, 0.4 at month 6 , and 0.3 at month 36 in the 5.0/1.25 mg group. The mean number of new T2 lesions acquired across all treatment groups was 0.6 at month 24 (since month 12) and 0.7 at month 36 (since month 24). Considering clinical outcomes at month 36 , the ARR was 0.20 and 0.21 in the fingolimod $1.25 \mathrm{mg}$ and $5.0 / 1.25 \mathrm{mg}$ groups, 
respectively, and 0.31 in the placebo/fingolimod group. The proportion of patients relapse-free at month 36 was $68 \%$ in the fingolimod $1.25 \mathrm{mg}$ group and $73 \%$ in the fingolimod $5.0 / 1.25 \mathrm{mg}$ group rather than an estimated $51 \%$ of patients in the placebo/fingolimod group at month 36 .

\section{Phase III studies}

On the basis of the results obtained from the Phase II studies, two multicenter, randomized, double-blind Phase III trials were designed. ${ }^{43,44}$ As the results suggest that the therapeutic benefits attributed to fingolimod might exceed those expected from approved disease-modifying injectable therapies such as IFN- $\beta$ or GA, the Trial Assessing Injectable Interferon versus FTY720 Oral in Relapsing-Remitting Multiple Sclerosis (TRANSFORMS) $^{43}$ was designed to directly test this hypothesis. In this 12-month, double-blind, double-dummy study, they randomly assigned 1292 RRMS patients between 18 and 55 years of age according to the McDonald Criteria, who had a recent history of at least one relapse in the last year before screening, to receive either oral fingolimod at a daily dose of either 1.25 or $0.5 \mathrm{mg}$ or intramuscular interferon beta-1a at a weekly dose of $30 \mu \mathrm{g}$. The primary efficacy endpoint was the ARR. Key secondary endpoints were the number of new or enlarged lesions on T2-weighted MRI scans at 12 months and the time to confirmed disability progression taken as a progression of disability that was sustained for at least 3 months. In all, 1153 patients (89\%) completed the study, and 1123 (87\%) continued to receive the assigned study drug. There was a significantly greater reduction in the ARR in both fingolimod groups than in the interferon group. The ARR was lower with fingolimod (0.5 mg: 0.16; $1.25 \mathrm{mg}$ : 0.20$)$ than with IFN-b-1a $(0.33 ; P<0.001)$. More patients treated with fingolimod remained free from relapses $(80 \%-83 \%)$ compared with IFNb-1a $(69 \% ; P<0.001)$. The proportion of patients with confirmed disability progression was low and similar in all groups $(6 \%-8 \%)$. Over the treatment period of 12 months, patients in both fingolimod groups had fewer new or enlarged hyperintense lesions on T2-weighted images than those receiving IFNb-1a (mean number, $0.5 \mathrm{mg}$ group 1.7; $1.25 \mathrm{mg}$ group 1.5; IFN-B group 2.6; $P<0.001$ and $P=0.004$, respectively). The number of patients free from $\mathrm{Gd}+$ lesions was also lower in those taking fingolimod (0.5 mg: 90.1\%; $1.25 \mathrm{mg}$ : 91.2\%) compared with those taking IFNb-1a $(80.8 \% ; P<0.001$ for both groups $) .{ }^{43}$

The second Phase III study investigating fingolimod was the FTY720 Research Evaluating Effects of Daily Oral Therapy in Multiple Sclerosis (FREEDOMS), ${ }^{44}$ a 24-month, double-blind, placebo-controlled randomized study.
One thousand, two hundred and seventy-two patients were enrolled, who had RRMS defined as the McDonald Criteria, between 18 to 55 years of age, having a score of 0 to 5.5 on the Expanded Disability Status Scale and had had one or more relapses in the previous year or two or more in the previous 2 years. Patients received oral fingolimod at a dose of $0.5 \mathrm{mg}$ or $1.25 \mathrm{mg}$ daily or placebo. As in the TRANSFORMS study, the primary endpoint was the ARR, and the secondary endpoint was represented by the time to disability progression. MRI measures of inflammation, burden of disease, and tissue destruction in patients were also analyzed. One thousand and thirty-three patients $(81.2 \%)$ completed the 24-month study. All clinical and MRI-related efficacy endpoints significantly favored both doses of fingolimod over placebo, and there were no significant differences in efficacy between the two fingolimod doses: the aggregate ARR was lower with fingolimod at a dose of $0.5 \mathrm{mg}(0.18)$ and fingolimod at a dose of $1.25 \mathrm{mg}(0.16)$ than with placebo (0.40), representing relative reductions of $54 \%$ and $60 \%$, respectively, in the aggregate ARR ( $P<0.001$ for both groups). In the fingolimod groups as compared with the placebo group, the time to first relapse was longer, the risk of relapse was reduced, and proportionately more patients remained free of relapse during the 24-month period. Fingolimod reduced the risk of disability progression, confirmed after 3 months, over the 24-month study period (hazard ratios: 0.68 for the 1.25 -mg dose and 0.70 for the 0.5 -mg dose, $P<0.02) .{ }^{44}$ The cumulative probability of disability progression (confirmed after 3 months) was $17.7 \%$ for $0.5 \mathrm{mg}$ of fingolimod, $16.6 \%$ for $1.25 \mathrm{mg}$ of fingolimod, and $24.1 \%$ for placebo. At month 24 , patients receiving fingolimod had fewer new or enlarged hyperintense lesions on T2-weighted images than those in the placebo group (mean number: 0.5 ; for $1.25 \mathrm{mg}$ : 2.5 ; for placebo: $9.8 ; P<0.001$ ). Fingolimod was also superior to placebo with regard to other MRI measures of disease activity as $\mathrm{Gd}+$ enhancing lesions. ${ }^{43}$ Interestingly, in patients treated with fingolimod, the reduction in brain volume was less than in patients treated with placebo.

\section{Safety and tolerability}

The safety profile of fingolimod has been extensively studied, and the available data indicate that the drug has a relatively good safety profile. It is clear that the incidence of AEs for fingolimod is dose-dependent. ${ }^{40-43,44}$ In the Phase III trials, the incidence of AEs was approximately the same across all study groups. AEs related to fingolimod included infections, particularly respiratory, urinary tract, and herpes virus infections, increased levels of alanine aminotransferase, 
bradycardia and atrioventricular block at the time of treatment initiation, hypertension, and macular edema. The incidence of serious AEs was comparable among the study groups, with the exception of the TRANSFORMS trial, ${ }^{42}$ in which serious AEs were more frequent in patients assigned to the higher dose of fingolimod $(1.25 \mathrm{mg} ; 11 \%)$ than in those receiving $0.5 \mathrm{mg}(7 \%)$.

However, the pathophysiology of macular edema in patients treated with fingolimod is still unclear; macular edema was confirmed in 13 patients receiving fingolimod in Phase III trials, of which 11 were treated with $1.25 \mathrm{mg}$. Most cases occurred within the first 3-4 months and resolved after treatment discontinuation..$^{43,44}$

As expected, the drug decreased peripheral blood lymphocyte counts to $20 \%-30 \%$ of baseline values. Lymphocyte counts remained stable throughout the treatment period, and returned to baseline values within weeks after treatment discontinuation. As a consequence of the effects of fingolimod on circulating lymphocyte, the drug apparently increased the risk of infections. In Phase III trials, the overall incidence of infections was similar across the study groups, between $51 \%-72 \%$. Mild and moderate upper and lower respiratory tract infections occurred more frequently among patients receiving fingolimod. In the FREEDOMS study, herpes virus infections were reported in similar proportions across study groups (1.25 mg: 5.8\%; $0.5 \mathrm{mg}$ : 8.7\%; placebo: 7.9\%). On the contrary, in the TRANSFORMS study, these were more common in the $1.25-\mathrm{mg}$ group (5.5\% of patients) than in the 0.5 -mg and IFN-b-1a groups ( $2.1 \%$ and $2.8 \%$, respectively). Most herpes virus infections were mild, but a total of six serious AEs were reported, including one case of fatal disseminated varicella zoster virus infection and one case of fatal herpes simplex virus type 1 encephalitis both in patients assigned to fingolimod $1.25 \mathrm{mg}$. Both patients were undergoing concomitant corticosteroid treatment when the infection occurred. ${ }^{43,44}$ Thus, a possible increase in the risk of reactivation of latent herpes should be investigated when considering fingolimod treatment. Besides lymphopenia, asymptomatic elevation of liver enzyme levels was the most frequent laboratory abnormality and occurred in a dose-dependent manner within the whole range of doses investigated. In clinical studies, alanine aminotransferase levels returned to normal values after treatment discontinuation. In all these cases, other signs or symptoms of significant hepatocellular injury were not observed. ${ }^{43,44}$ Moreover, fingolimod induced a small, dose-dependent increase in the airway resistance upon treatment initiation, with no evidence of further progression with continuous dosing. ${ }^{40-44}$
As was expected according to previous findings, rarely symptomatic, dose-dependent reduction in heart rate was observed within 6 hours after administration of the first dose. This drop in heart rate was already evident after 1 hour post dosing, reached a maximum mean reduction of approximately $10 \mathrm{bpm}$ at $4-5$ hours, and began to attenuate at 6 hours, returning to baseline values. ${ }^{43,44}$

In Phase III trials, symptomatic bradycardia after the first dose of fingolimod, mainly dizziness, chest discomfort, or palpitations, was observed in $<1 \%$ of patients. No cases of syncope have been observed. Most events were mild-to-moderate in severity and resolved within 24 hours without requiring pharmacological interventions. There were no episodes of symptomatic bradycardia occurring beyond 24 hours and no clinically significant effects on heart rate were observed with sustained administration of the drug. ${ }^{43,44}$ Although during these clinical trials, pharmacological treatment was not required to treat bradycardia, it has been suggested that intravenous atropine can ameliorate the negative effect of fingolimod on cardiac rhythm. ${ }^{45}$ In addition to transient changes in cardiac rhythm, fingolimod induced cardiac conduction abnormalities. In the Phase III trials, first- and second-degree atrioventricular blocks were infrequently reported $(0.4 \%-1.4 \%$ of patients $)$ and these were not symptomatic. However, in the FREEDOMS study, electrocardiography performed on day 1 post-dosing revealed first- and second-degree atrioventricular block in 7\% and $0.6 \%$ of patients, respectively. No effect on atrioventricular conduction was observed with continued treatment beyond 24 hours. ${ }^{43,44}$ Initial administration of fingolimod was also associated with a mild reduction in mean arterial blood pressure within 4-5 hours post-dosing. This transient reduction in mean arterial pressure was followed by a small and sustained increase (2-3 mmHg over the baseline values) during the first 6 months of treatment, with no further changes in the subsequent months. In the Phase III trials, hypertension was reported in $4 \%-6 \%$ of participants. ${ }^{43,44}$

Malignant neoplasms were reported in patients undergoing therapy with fingolimod in the Phase III trials, including localized skin cancer (Bowen's disease: 1 case; basal cell carcinoma: 10 cases; malignant melanoma: 4 cases), all of which were successfully excised, and breast cancer ( 5 cases). One woman died from metastatic breast cancer 10 months after discontinuing fingolimod. ${ }^{43}$ Both skin and breast cancer were also reported in the control groups ( 6 and 3 cases in total, respectively). The number of events was not enough to establish a statistical association between fingolimod and the risk of cancer in clinical trials. However, further long-term 
observation is needed before definitive conclusions can be detected.

Besides more frequent serious AEs, there were two cases of particular interest during these clinical trials. One case of posterior reversible encephalopathy syndrome occurred in a woman with no evident predisposing factors after 10 weeks of treatment with $5 \mathrm{mg}$ of fingolimod. The symptoms and MRI abnormalities improved 72 hours after discontinuation of medication, leaving residual neurological deficits. ${ }^{44}$

A case of temporo-occipital hemorrhagic and centrally necrotic focal encephalitis of unknown etiology was reported in a woman after 7 months of treatment with $1.25 \mathrm{mg}$ of fingolimod. Although bacterial and viral causes were excluded, antimicrobial treatment was administered. The patient recovered with sequelae. ${ }^{46}$

\section{Conclusion}

While the availability of oral therapies has been much anticipated by physicians and patients, in the clinical practice, neurologists will need to be cautious in selecting a therapy that may appear to have efficacy and convenience advantages versus current therapies, but may also carry unexpected safety and tolerability concerns. We do not yet know whether or not AEs seen in the recently published trials of fingolimod are the only safety issues to consider. The decision to use these new therapies will most likely be based on an overall assessment of efficacy, safety, tolerability, and adherence over the postmarketing period.

Keeping in mind the two different approval releases in the US (first-line treatment) and European countries (secondline treatment), ${ }^{47}$ the following key questions still need to be answered before the treating neurologist is able to make evidence-based decisions:

- Considering the approval in the US: does fingolimod have a positive benefit-risk ratio compared with the established first-line DMDs?

- Which treatment shall we choose?

With regard to the first question, we have learned from the still unsolved and ongoing natalizumab studies that we are not able to anticipate the long-term safety.

Targeting lymphatic S1P1 receptor is preferential to targeting naïve and central memory $\mathrm{T}$ cells, except for the effector memory $\mathrm{T}$ cell population. This could potentially result in a selective mode of action targeting autoimmunity and preserving key responses of the adaptive immunity relevant for viral defense. However, these concepts and treatment rationales still need to be confirmed by data from the postmarketing period. Occurrence of herpes virus infections, as seen among patients receiving fingolimod, indicate a potential alteration of endogenous viral immunosurveillance. Further safety concerns include the risk of macular edema, the effect on lung function, and cancers. In addition, several cases of cardiological AEs have been reported, including symptomatic bradycardia after the first dose. Some deaths were also recently reported and further investigations are ongoing in order to define the exact relationship between these deaths and the use of fingolimod. This becomes more meaningful if we consider that the European Medicines Agency has recently advised clinicians to increase monitoring of patients after the first dose. ${ }^{48}$

Moreover, data on teratogenicity is limited and although effective contraceptive measures are mandatory during and for 2 months after treatment discontinuation, cases of pregnancy in this cohort of patients will most likely occur, with uncertain consequences for the unborn child. Newer agents, which are more selective for the different types of $\mathrm{S} 1 \mathrm{P}$ receptors, are currently in development to minimize the AEs observed with fingolimod. ${ }^{49}$

Therefore, will the benefits outweigh the risks during a long-term period of treatment in the individual patient? We believe that at the moment, the data available are not sufficient to answer this question. Therefore, in our opinion, these issues will need to be discussed with the well-informed patient before considering fingolimod as a first-line choice in the treatment of MS.

On the other hand, European countries now have at their disposal two second-line treatment options (natalizumab and fingolimod), for highly active MS patients or patients not tolerating or not responding to first-line DMDs. Both drugs have been proven to be highly effective, although direct comparative head-to-head clinical trials have not yet been undertaken. Thus, with regard to the second key question - which compound to choose for this indication - the final decision will be based on benefit-risk considerations in the individual patient. The first prerequisite for an evidencebased decision for the individual should be head-to-head clinical trials comparing the two compounds in efficacy. Postmarketing experience will be able to demonstrate the safety profile of fingolimod, while attempts to stratify patients at risk of PML treated with natalizumab are on the way. In future we foresee the possibility of switching therapy from natalizumab to fingolimod in those patients who present a high-risk profile in continuing therapy with natalizumab.

These approaches may in the future lead toward individualized treatment, where data from the patient's history and exposure to specific infectious agents (such as JC virus serology) 
could be taken into account to find the best treatment for the individual patient. Until these promising future tools are validated and have been proven to be applicable in daily clinical practice, the correct individual treatment decisions can only be made via dialog with the well-informed patient.

\section{Disclosure}

The authors report no conflicts of interest in this work.

\section{References}

1. Weinshenker BG, Bass B, Rice GP, et al. The natural history of multiple sclerosis: a geographically based study. I. Clinical course and disability. Brain. 1989;112(Pt 1):133-146.

2. Murray TJ. Diagnosis and treatment of multiple sclerosis. BMJ. 2006; 332:525-527.

3. Compston A, Coles A. Multiple sclerosis. Lancet. 2008;372:1502-1517.

4. Confavreux C, Vukusic S. Natural history of multiple sclerosis: a unifying concept. Brain. 2006;129:606-616.

5. Lassmann H, Bruck W, Lucchinetti CF. The immunopathology of multiple sclerosis: an overview. Brain Pathol. 2007;17:210-218.

6. Frohman EM, Racke MK, Raine CS. Multiple sclerosis - the plaque and its pathogenesis. $N$ Engl J Med. 2006;354:942-955.

7. Galetta SL, Markowitz C. US FDA-approved disease-modifying treatments for multiple sclerosis: review of adverse effect profiles. CNS Drugs. 2005;19:239-252.

8. US Food and Drug Administration. FDA approves first oral drug to reduce MS relapses [press release]. Silver Spring, MD: US Food and Drug Administration. September 22, 2010. Available at: http://www. fda.gov/NewsEvents/Newsroom/PressAnnouncements/ucm 226755. htm. Accessed February 27, 2012.

9. Therapeutic Goods Administration, Department of Health and Ageing (Australia). Australian Public Assessment Report for Cladribine Tablets. July 2011. Available at: http://www.tga.gov.au/pdf/auspar/ auspar-movectro.pdf. Accessed February 27, 2012.

10. Giovannoni G, Comi G, Cook S, et al; CLARITY Study Group. A placebo controlled trial of oral cladribine for relapsing multiple sclerosis. N Engl J Med. 2010;362:416-426.

11. Cook S, Vermersch P, Comi G, et al. Safety and tolerability of cladribine tablets in multiple sclerosis: the CLARITY (CLAdRIbine Tablets treating multiple sclerosis orallY) study. Mult Scler. 2011;17(5):578-593.

12. Ockenfels HM, Schultewolter T, Ockenfels G, Funk R, Goos M. The antipsoriatic agent dimethylfumarate immunomodulates T-cell cytokine secretion and inhibits cytokines of the psoriatic cytokine network. $\mathrm{Br} J$ Dermatol. 1998;139,390-395.

13. Schimrigk S, Brune N, Hellwig K, et al. Oral fumaric acid esters for the treatment of active multiple sclerosis: an open-label, baseline-controlled pilot study. Eur J Neurol. 2006;13(6):604-610.

14. Kappos L, Gold R, Miller DH, et al; BG-12 Phase IIb Study Investigators. Efficacy and safety of oral fumarate in patients with relapsing-remitting multiple sclerosis: a multicentre, randomised, double-blind, placebocontrolled phase IIb study. Lancet. 2008;372(9648):1463-1472.

15. Bruneau JM, Yea CM, Spinella-Jeagle S, et al. Purification of human dihydroorotate dehydrogenase and its inhibition by A77 1726, the active metabolite of leflunomide. Biochem. 1998;J336:299-303.

16. Korn T, Toyka K, Hartung HP, Jung S. Suppression of experimental autoimmune neuritis by leflunomide. Brain. 2001;124:1791-1802.

17. Korn T, Magnus T, Toyka K, Jung S. Modulation of effector cell functions in experimental autoimmune encephalomyelitis by leflunomide - mechanisms independent of pyrimidine depletion. J Leukoc Biol. 2004;76:950-960.

18. O'Connor PW, Li D, Freedmann MS, et al. A phase II study of the safety and efficacy of teriflunomide in multiple sclerosis with relapses. Neurology. 2006;66:894-900.
19. O'Connor PW, Wolinsky JS, Confavreux C, et al. A placebo-controlled phase III trial (TEMSO) of oral teriflunomide in relapsing multiple sclerosis: clinical efficacy and safety outcomes. Abstract presented at: ECTRIMS 2010. Proceedings of the 26th Congress of the European Committee for Treatment and Research in Multiple Sclerosis; October 15, 2010; Gothenburg, Sweden.

20. Yang JS, Xu LY, Xiao BG, Hedlund G, Link H. Laquinimod (ABR215062) suppresses the development of experimental autoimmune encephalomyelitis, modulates the Th1/Th2 balance and induces the Th3 cytokine TGF $\beta$ in Lewis rats. J Neuroimmunol. 2004;156:3-9.

21. Comi G, Pulizzi A, Rovaris M, et al. Effect of laquinimod on MRImonitored disease activity in patients with relapsing-remitting multiple sclerosis: a multicentre, randomised, double-blind, placebo-controlled phase IIb study. Lancet. 2008;371:2085-2092.

22. Comi G, Jeffrey D, Kappos L, et al. Oral laquinimod reduced relapse rate and delayed progression of disability in ALLEGRO, a placebo-controlled phase III trial for relapsing-remitting multiple sclerosis. Abstract presented at: AAN 2011. American Academy of Neurology 63rd Annual Meeting; April 15, 2011; Honolulu, HI. Abst \#P05.288.

23. Vollmer TL, Soelberg Sorensen P. Arnold DL on behalf of the BRAVO study. A placebo-controlled and active comparator phase III trial (BRAVO) for relapsing-remitting multiple sclerosis [abstract]. Mult Scler. 2011;17:S507-524.

24. Brinkmann V. FTY720 (fingolimod) in multiple sclerosis: therapeutic effects in the immune and the central nervous system. Br J Pharmacol. 2009; 158:1173-1182.

25. Foster CA, Howard LM, Schweitzer A, et al. Brain penetration of the oral immunomodulatory drug FTY720 and its phosphorylation in the central nervous system during experimental autoimmune encephalomyelitis: consequences for mode of action in multiple sclerosis. J Pharmacol Exp Ther. 2007;323:469-475.

26. Salvadori M, Budde K, Charpentier B, et al. FTY720 versus MMF with cyclosporine in de novo renal transplantation: a 1-year, randomized controlled trial in Europe and Australasia. Am J Transplant. 2006;6:2912-2921.

27. Fujita T, Inoue K, Yamamoto S, et al. Fungal metabolites. Part 11. A potent immunosuppressive activity found in Isaria sinclairii metabolite. J Antibiot (Tokyo). 1994;47:208-215.

28. Chun J, Hartung HP. Mechanism of action of oral fingolimod (FTY720) in multiple sclerosis. Clin Neuropharmacol. 2010;33(2): $91-110$.

29. Takabe K, Paugh SW, Milstien S, Spiegel S. "Inside-out" signaling of sphingosine-1-phosphate: therapeutic targets. Pharmacol Rev. 2008;60:181-195.

30. Sanchez T, Hla T. Structural and functional characteristics of S1P receptors. J Cell Biochem. 2004;92(5):913-922.

31. Dev KK, Mullershausen F, Mattes H, et al. Brain sphingosine-1phosphate receptors: implication for FTY720 in the treatment of multiple sclerosis. Pharmacol Ther. 2008;117:77-93.

32. Brinkmann V. Sphingosine 1-phosphate receptors in health and disease: mechanistic insights from gene deletion studies and reverse pharmacology. Pharmacol Ther. 2007;115:84-105.

33. Schwab SR, Cyster JG. Finding a way out: lymphocyte egress from lymphoid organs. Nat Immunol. 2007;8(12):1295-1301.

34. Ishii I, Fukushima N, Ye X, Chun J. Lysophospholipid receptors: signaling and biology. Annu Rev Biochem. 2004;73:321-354.

35. Oo ML, Thangada S, Wu MT, et al. Immunosuppressive and antiangiogenic sphingosine 1-phosphate receptor-agonists induce ubiquitinylation and proteasomal degradation of the receptor. J Biol Chem. 2007;282:9082-9089.

36. Kovarik JM, Schmouder R, Barilla D, Wang Y, Kraus G. Multiple-dose FTY720: tolerability, pharmacokinetics, and lymphocyte responses in healthy subjects. J Clin Pharmacol. 2004;44:532-537.

37. Budde K, L Schmouder R, Nashan B, et al. First human trial of FTY720, a novel immunomodulator, in stable renal transplant patients. J Am Soc Nephrol. 2002;13:1073-1083. 
38. Kataoka H, Sugahara K, Shimano K, et al. FTY720, sphingosine 1-phosphate receptor modulator, ameliorates experimental autoimmune encephalomyelitis by inhibition of T cell infiltration. Cell Mol Immunol. 2005;2(6):439-448.

39. Fujino M, Funeshima N, Kitazawa Y, et al. Amelioration of experimental autoimmune encephalomyelitis in Lewis rats by FTY 720 treatment. J Pharmacol Exp Ther. 2003;305(1):70-77.

40. Kappos L, Antel J, Comi G, et al. Oral fingolimod (FTY720) for relapsing multiple sclerosis. N Engl J Med. 2006;355(11):1124-1140.

41. O’Connor P, Comi G, Montalban X, et al. Oral fingolimod (FTY720) in multiple sclerosis: two-year results of a phase II extension study. Neurology. 2009;72(1):73-79.

42. Comi G, O’Connor P, Montalban X, et al. Phase II study of oral fingolimod (FTY720) in multiple sclerosis: 3-year results. Mult Scler. 2010;16(2):197-207.

43. Cohen JA, Barkhof F, Comi G, et al. Oral fingolimod or intramuscular interferon for relapsing multiple sclerosis. $N \mathrm{Engl} \mathrm{J} \mathrm{Med.}$ 2010;362(5):402-415.

44. Kappos L, Radue EW, O’Connor P, et al. A placebo-controlled trial of oral fingolimod in relapsing multiple sclerosis. $N$ Engl J Med. 2010; 362(5):387-401.
45. Kovarik JM, Slade A, Riviere GJ, et al. The ability of atropine to prevent and reverse the negative chronotropic effect of fingolimod in healthy subjects. Br J Clin Pharmacol. 2008;66(2):199-206.

46. Leypoldt F, Münchau A, Moeller F, Bester M, Gerloff C, Heesen C. Hemorrhaging focal encephalitis under fingolimod (FTY720) treatment: a case report. Neurology. 2009;72(11):1022-1024.

47. European Medicines Agency EPAR summary: available from: http:// www.ema.europa.eu/docs/en_GB/document_library/EPAR_-_Summary_for_the_public/human/002202/WC500104530.pdf. Accessed February 27, 2012.

48. European Medicines Agency. Questions and answers on the ongoing review of Gilenya (fingolimod). January 19, 2012. Available from http:// www.ema.europa.eu/docs/en_GB/document_library/Medicine_QA/ human/002202/WC500120704.pdf. Accessed February 27, 2012.

49. Kasper LH, Due BR; ONO-4641 Study Group. A phase I study to evaluate safety, tolerability and pharmacological properties of a selective sphingosine-1-phosphate (S1P) receptor agonist ONO-4641 in patients with multiple sclerosis [poster no. P991]. Presented at ECTRIMS 2010. Proceedings of the 26th Congress of the European Committee for the Treatment and Research in Multiple Sclerosis; October 15, 2010; Gothenburg, Sweden.
Drug Design, Development and Therapy

\section{Publish your work in this journal}

Drug Design, Development and Therapy is an international, peerreviewed open-access journal that spans the spectrum of drug design and development through to clinical applications. Clinical outcomes, patient safety, and programs for the development and effective, safe, and sustained use of medicines are a feature of the journal, which

\section{Dovepress}

has also been accepted for indexing on PubMed Central. The manuscript management system is completely online and includes a very quick and fair peer-review system, which is all easy to use. Visit http://www.dovepress.com/testimonials.php to read real quotes from published authors.

Submit your manuscript here: http://www.dovepress.com/drug-design-development-and-therapy-journal 